\title{
Ultrastructure of the intrauterine eggs of Didymobothrium rudolphii (Monticelli, 1890) (Cestoda, Spathebothriidea, Acrobothriidae) and its phylogenetic implications**
}

\author{
Zdzisław Świderski ${ }^{1,2 *}$, David I. Gibson ${ }^{3}$, Maria João Santos ${ }^{4}$ and Larisa G. Poddubnaya ${ }^{5}$
}

${ }^{1}$ W. Stefański Institute of Parasitology, Polish Academy of Sciences, 00-818 Warsaw, Poland;

${ }^{2}$ Department of General Biology and Parasitology, Warsaw Medical University, Warsaw, Poland;

${ }^{3}$ Department of Zoology, Natural History Museum, Cromwell Road, London, SW7 5BD, UK;

${ }^{4}$ Universidade do Porto, Faculdade de Ciências, Departamento de Biologia, Rua do Campo Alegre, s/n, FC4, 4169-007, Porto and CIMAR/CIIMAR-Centro Interdisciplinar de Investigação Marinha e Ambiental, Rua dos Bragas, 177, 4050-123 Porto, Portugal;

${ }^{5}$ Institute of Biology of Inland Waters, Russian Academy of Sciences, 152742 Borok, Yaroslavl Province, Russia

\begin{abstract}
The intrauterine polylecithal eggs of the spathebothriidean cestode Didymobothrium rudolphii (Monticelli, 1890) were examined by means of transmission electron microscopy (TEM). Each unembryonated egg is composed of a fertilised oocyte or ovum and several vitelline cells, all surrounded by a newly formed shell. The lumen of the proximal uterus is packed with unutilised vitelline material and eggs at different stages of shell formation. In the proximal region of the uterus, the fertilised oocytes, initially surrounded by dense, discontinuous islands of eggshell material and containing long axonemes of spermatozoa in their cytoplasm, were frequently observed. Sperm axonemes also remain in the oocyte cytoplasm of eggs surrounded by a thick electron-dense shell until the sperm nucleus is transformed into a male pronucleus. Despite the fact that the two-pronuclei stage and cell divisions within the eggs of $D$. rudolphii were never observed, individual eggs containing several blastomeres of different sizes were seen in the middle and distal regions of the uterus. This provides indirect evidence that at least a few initial cleavage divisions must take place in the intrauterine eggs and direct evidence that the early embryonic development of D. rudolphii starts in utero. The several vitellocytes present in each egg contain nutritive reserves for the developing embryos; these are composed mainly of numerous lipid droplets and a moderate amount of glycogen. In the eggs containing early embryos composed of several blastomeres, the cytoplasm of the degenerating vitellocytes exhibits the presence of so-called 'foci of cytoplasmic degradation', which appear to be involved in the autolytic process of the vitellocyte cell components and inclusions, such as a high accumulation of lipids and glycogen. This progressive degeneration of the vitellocytes, considered as an example of programmed cell death or apoptosis, likely contributes towards the resorption of nutritive reserves by the developing embryo. Some of the results of this study are commented upon in relation to the affiliation of the spathebothriideans with other lower cestode groups.
\end{abstract}

\section{Keywords}

Cestoda, Spathebothriidea, Didymobothrium rudolphii, intrauterine eggs, fertilisation, eggshell formation, ultrastructure

\section{Introduction}

The Spathebothriidea, unsegmented but polyzoic tapeworms, occupies a basal position in the phylogeny and evolution of cestodes (Gibson 1994, Hoberg et al. 2001, Mariaux and Olson 2001, Olson et al. 2001, Olson and Tkach 2005, Waeschen- bach et al. 2007) and potentially represent the most basal lineage of the Eucestoda. Consequently, its members represent important taxa for understanding the origin of segmentation (i.e., proglottidisation). The group comprises five genera, the taxonomy of which has often been controversial (e.g. Burt and Sandeman 1969, Gibson 1994, Protasova and Roytman 1995),

\footnotetext{
*Corresponding author: z.swider@twarda.pan.pl
}

\footnotetext{
**Dedicated to the memory of Professor Maria N. Dubinina on the occasion of 100th Anniversary of her birthday
} 
as they exhibit few gross morphological differences. They are parasites of various groups of freshwater and marine teleost (Salmoniformes, Pleuronectiformes and Scorpaeniformes) and chondrostean (Acipenseriformes) fishes (Gibson 1994). Their common characteristic is the lack of external segmentation (i.e., discretely demarcated proglottids), but they have multiple sets of reproductive organs situated along their bodies; otherwise differences are mainly in the form of the scolex and the situation of the genital pores.

Didymobothrium rudolphii (Monticelli, 1890) is a parasite of soleid teleosts from the western Mediterranean and the Atlantic coast of southern Europe. Didymobothrium Nybelin, 1922 was erected on the basis of genital apertures alternating between the dorsal and ventral surfaces. Burt and Sandeman (1969) considered both Didymobothrium and Diplocotyle Krabbe, 1874 as synonyms of Bothrimonus Duvernoy, 1842, and Protasova and Roytman (1995) considered Didymobothrium a nomen dubium and $D$. rudolphii a potential synonym of Diplocotyle olrikii Krabbe, 1874. On the other hand, Gibson (1994) recognised three independent genera: Didymobothrium from soleids, Diplocotyle from euryhaline teleosts (especially salmonids and pleuronectids) and Bothrimonus from acipenserid chondrosteans based on the form of the scolex and the dorsoventral arrangement of the genital pores. Adding to the complexity of problems concerning the validity of spathebothriidean taxa, it is likely that some or all may comprise a complex of cryptic species, as has been shown by the allozyme studies by Renaud and Gabrion (1988) in which D. rudolphii (referred to as Bothrimonus nylandicus Schneider, 1902) from soleids in the western Mediterranean and eastern Atlantic was found to comprise two sympatric, sibling species. Furthermore, Marques et al. (2007) recently demonstrated the presence of two distinct genotypes of $D$. rudolphii along the Portuguese coast using two molecular markers (large-subunit and ITS rDNA) that correlated with statistically significant differences in the overall length and width of the otherwise cryptic forms.

Detailed ultrastructural studies of Didymobothrium are limited to works on the ovary, ovicapt and oviduct (Poddubnaya et al. 2007) and the vitellocytes (Poddubnaya et al. 2006). To date, there has been no information on the TEM ultrastructure of intrauterine eggs of spathebothriidean cestodes. Information on the intrauterine eggs is restricted to two SEM micrographs of Marques et al. (2007); these authors indicated that the eggs of $D$. rudolphii are $25-42 \times 14-22 \mu \mathrm{m}$ in size, and their SEM observations revealed a rough shell surface and the presence of an operculum at their more rounded pole and a tuft of filaments at their narrower pole. So far, the TEM studies of the eggs of the 'lower' cestodes have been impeded by technical difficulties, including the procurement of eggs with well-fixed contents, the infiltration of embedding media and in the cutting of the thick, hard shells.

The aims of the present study are: (A) to describe and characterise the ultrastructure of the intrauterine eggs of D. rudolphii, with particular attention to (a) shell formation and advanced stages of oocyte fertilisation within the proximal uterus; (b) the composition and amount of vitelline material in these polylecithal eggs, which form important nutritive reserves for the developing embryos in the external aquatic environment; (B) to compare the ultrastructure of the intrauterine eggs of D. rudolphii with that described for eggs of other lower cestodes, particularly the Caryophyllidea and former 'Pseudophyllidea', and (C) to establish whether or not such characters as egg poly- or oligolecithality and the different degrees of ovoviviparity observed in cestode embryonic development might represent additional characters for the analysis of cestode phylogeny, evolution and systematics and supplementary features for the recognition of divergent taxa.

\section{Materials and methods}

Adult specimens of Didymobothrium rudolphii were collected from the intestine of Solea lascaris on the Atlantic coast of northern Portugal off Aveiro during September, 2005. All specimens examined correspond to the 'common form' of D. rudolphii, as defined by Marques et al. (2007). The worms were fixed in $3 \%$ glutaraldehyde in $0.1 \mathrm{M}$ phosphate buffer $\left(\mathrm{pH} \mathrm{7.2)}\right.$ for 20 days at $5^{\circ} \mathrm{C}$. They were then transported to Russia and processed by one of us (LGP). Postfixation followed in $1 \%$ osmium tetroxide in $0.1 \mathrm{M}$ phosphate buffer for $1 \mathrm{~h}$ at $5^{\circ} \mathrm{C}$. The material was then dehydrated in a graded series of ethanol and acetone and embedded in Araldite and Epon. Ultrathin sections were stained with uranyl acetate and lead citrate. They were then examined in a JEOL-1011 transmission electron microscope operating at $80 \mathrm{kV}$.

\section{Results}

The tubular, convoluted uterus of Didymobothrium rudolphii is usually filled with polylecithal eggs (Fig. 1) at varying degrees of maturity throughout its length. Most eggs are composed of an ovum and about 7-10 vitellocytes, all surrounded by the shell at diffent degrees of formation and consolidation.

\section{Stages of eggshell formation and fertilisation in the proximal} uterus

The early stages of oocyte fertilisation and eggshell formation were not intended to be examined in detail in this study. How-

\footnotetext{
${ }^{1}$ The name 'Pseudophyllidea', in inverted commas, is used in this work, although it is recognised that this order has been recently subdivided into the Bothriocephalidea and the Diphyllobothriidea (see Kuchta et al. 2008). This is for ease of discussion in relation to earlier work which refers to the older ordinal concept.
} 


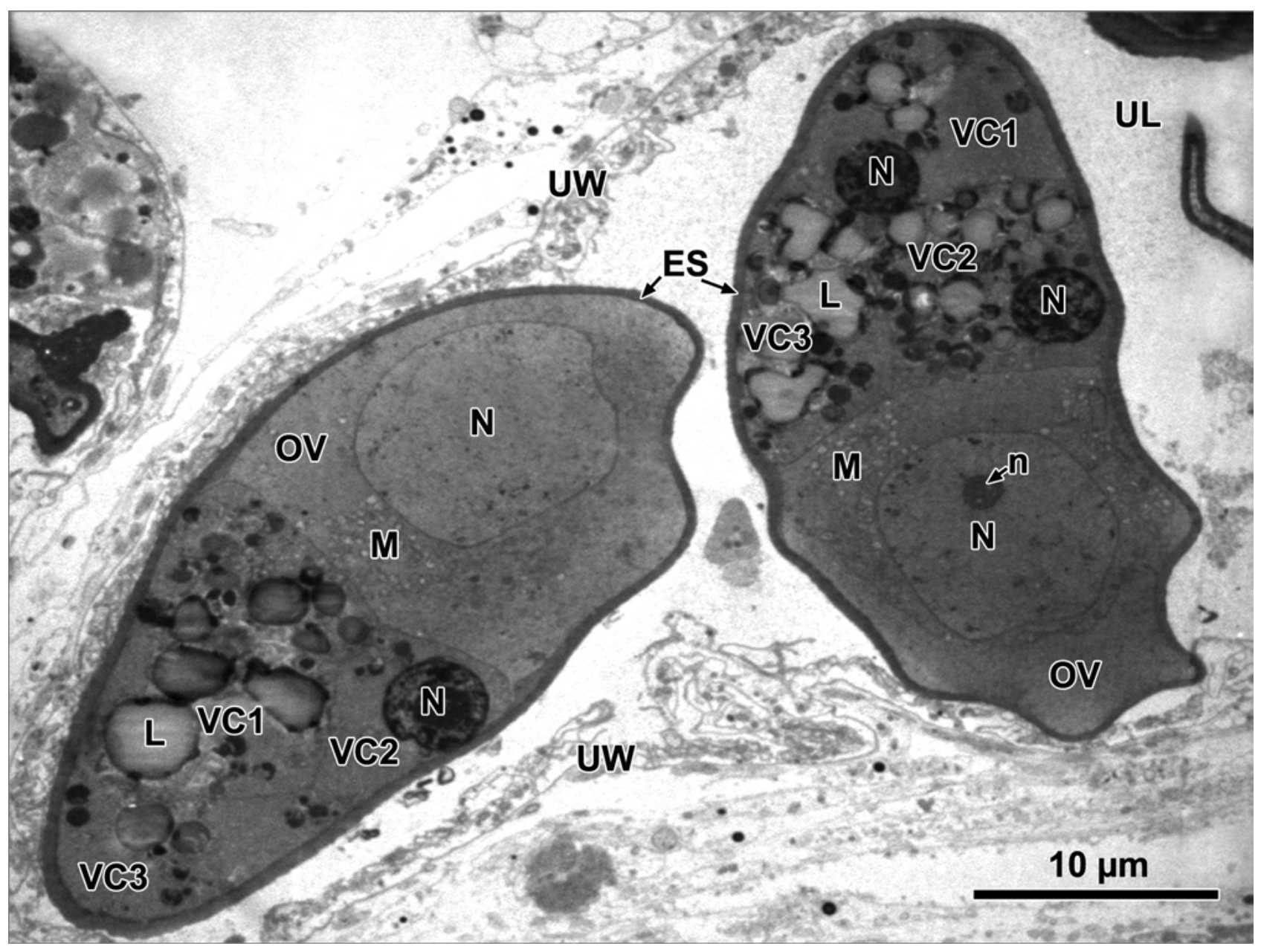

Fig. 1. Low magnification TEM micrograph illustrating the general topography of two unembryonated eggs of Didymobothrium rudolphii in the proximal region of the uterus. Note: (a) the electron-lucent cytoplasm and nucleoplasm of the fertilised oocyte or ovum; (b) the presence of a nucleolus in the oocyte nucleus of the egg on the right side; (c) three vitellocytes present in the ultrathin section of each egg, all of them being situated at the opposite pole to that occupied by the ovum; (d) the presence of numerous osmiophobic lipid droplets and, dispersed among them, small irregularly shaped dark bodies which represent foci of cytoplasmic degradation. Compare the size and electron density of the dark, compact nuclei of the vitellocytes with that of the oocyte or ovum. Abbreviations to all figures: B - blastomeres, BE - degenerating 'black eggs', ES - eggshell, ESI - eggshell islands of dense, shell-forming material, FCD - foci of cytoplasmic degradation, G - glycogen, GC - Golgi complexes, GER - granular endoplasmic reticulum, L - lipid droplets, $\mathrm{M}$ - mitochondrion, $\mathrm{N}$ - nucleus, $\mathrm{n}-$ nucleolus, $\mathrm{OV}$ - ovum or fertilised oocyte; $\mathrm{OM}$ - oocyte membrane, PEF - polar egg filaments, SE - narrow end of the egg, Sp - sperm axoneme, $\mathrm{UG}$ - uterine glands, UL - uterine lumen, UW - uterine wall, VC - vitellocytes with their consecutive numbers on one section

ever, various degrees of shell formation and advanced stages of fertilisation were observed in the uterus (Fig. 2A, B). With reference to shell formation, it can be seen in Figure 2A that one pole of the egg is surrounded by small, discontinuous islands of electron-dense shell material, whereas the opposite pole is already covered by a rather thick, continuous and solid layer of electron-dense shell. It is interesting to note that the two other eggs, situated on either side of the egg in the process of shell formation, already exhibit very thick electron-dense shells. Within the lumen of the proximal uterus, unutilised vitellocytes and isolated vitelline material (shell globules clusters, lipid droplets and glycogen) can also be seen.

The fertilised oocyte in Figure 2A, B contains sections of sperm axonemes, which indicate that this is an interesting ex- ample of an advanced stage of oocyte fertilisation. Under higher magnification (Fig. 2B), numerous spherical mitochondria, ribosomes or polysomes and several Golgi complexes are apparent. The spherical nucleus contains moderately electron-dense nucleoplasm with very few small islands of heterochromatin; its nuclear membrane is perforated by numerous nuclear pores (Fig. 2B).

\section{Ultrastructural characteristics of the unembryonated egg}

Figure 3 shows a moderately electron-dense cytoplasm of the oocyte, within which are several mitochondria, numerous ribosomes and a very few cisternae of the granular endoplasmic reticulum (GER). At high magnification (Fig. 3A, B) a 

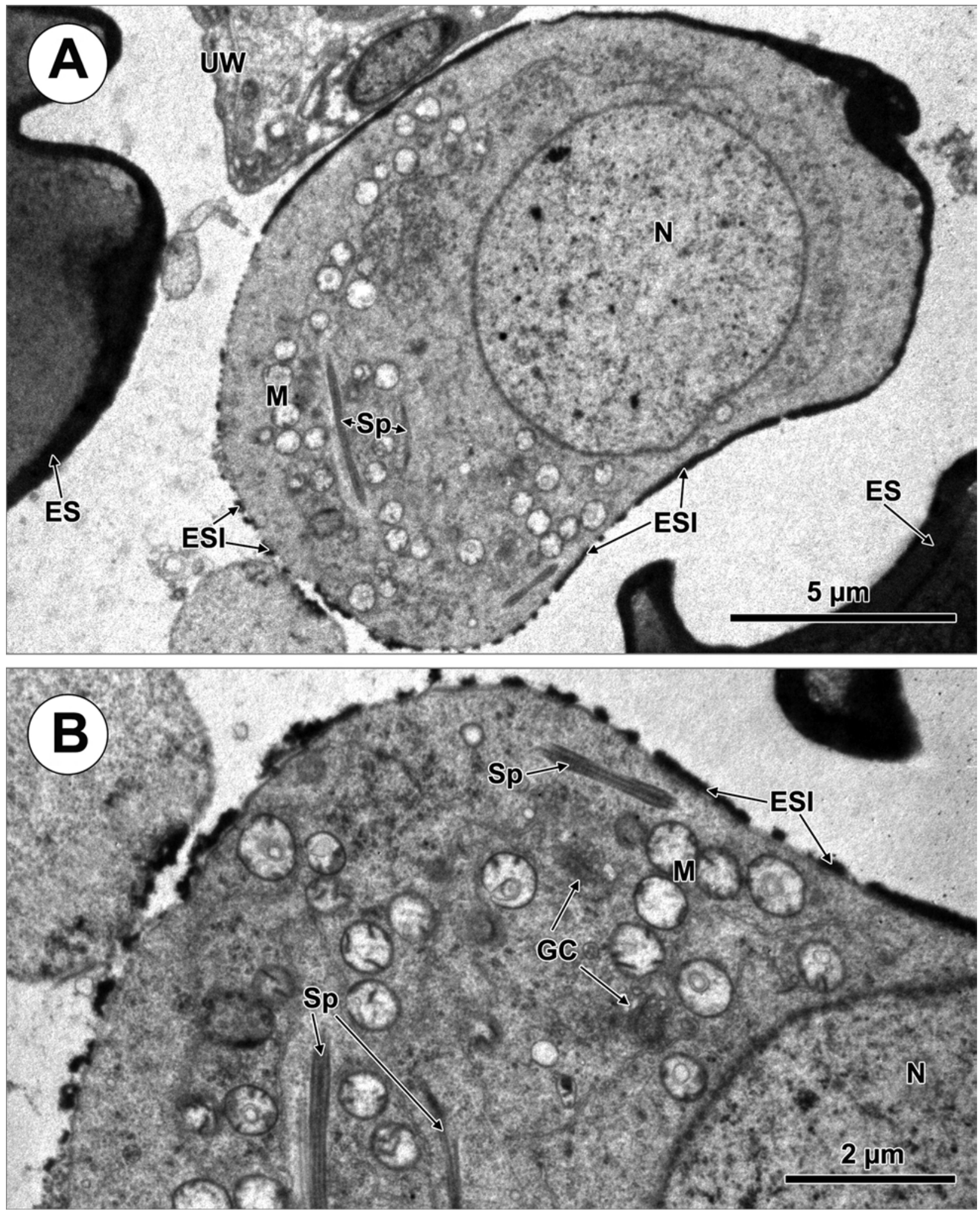

Fig. 2A and B. Fertlised oocyte in the proximal region of the uterus of Didymobothrium rudolphii showing consecutive stages of eggshell formation. Note: (a) one pole of the egg still surrounded by small discontinuous islands of electron-dense shell material and its opposite pole already covered by a thick, continuous and solid layer of the electron-dense shell; (b) parts of two eggs, situated one on either side of the central egg, already showing very thick electron-dense shells; (c) three sections of sperm axonemes, numerous mitochondria, ribosomes or polysomes and several Golgi complexes in the cytoplasm of the oocyte; (d) a spherical nucleus with a moderately electron-dense nucleoplasm and a few small islands of heterochromatin; (e) the presence of numerous nuclear pores in the oocyte nuclear membrane 

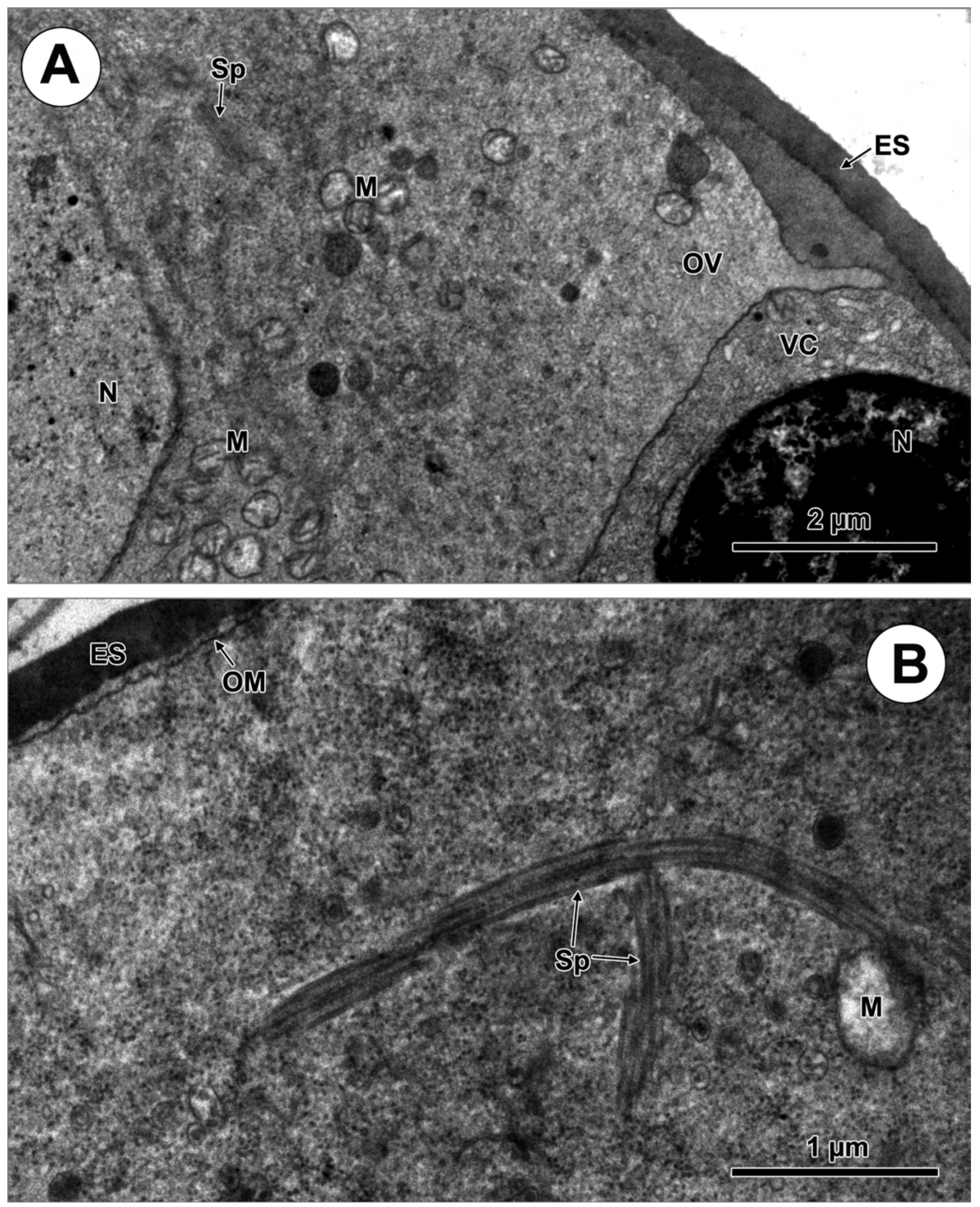

Fig. 3 A and B. Ultrastructural details of the ovum and vitellocytes in unembryonated eggs of Didymobothrium rudolphii. Note: (a) moderately electron-dense cytoplasm and nucleoplasm of the oocyte; (b) the presence of several mitochondria, numerous ribosomes and a sperm axoneme in the oocyte cytoplasm; (c) the presence of the oocyte plasma membrane situated directly beneath the shell. In Fig. 3A, compare the differences in the ultrastructure of the nuclei of the oocyte (on the left) and the vitellocyte (lower right corner) 

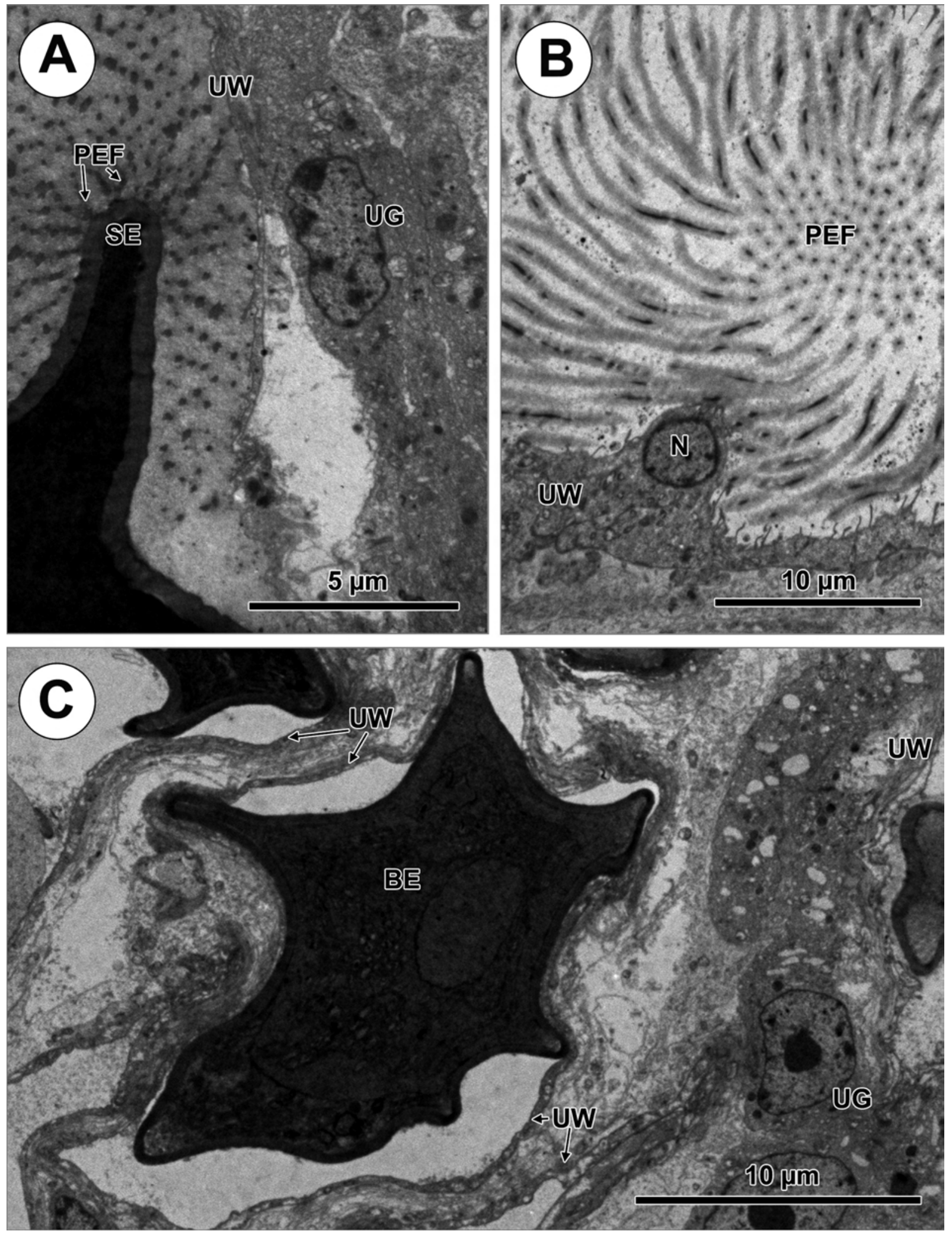

Fig. 4A-C. Ultrastructure of the polar filaments and degenerating 'black eggs' of Didymobothrium rudolphii. Note: (a) the narrower end of the egg with numerous polar filaments attached to its shell (Fig. 4A); (b) a tuft of egg polar filaments in the uterine lumen, with their longitudinal, oblique and cross-sections showing two ultrastructural components: a very thin, highly electron-dense core surrounded by a moderately electron-dense cortex (Fig. 4B); (c) an irregularly shaped, shrunken egg, which represents a degenerating egg, i.e. a so-called 'black egg' (Fig. 4C), which are quite common in this species 

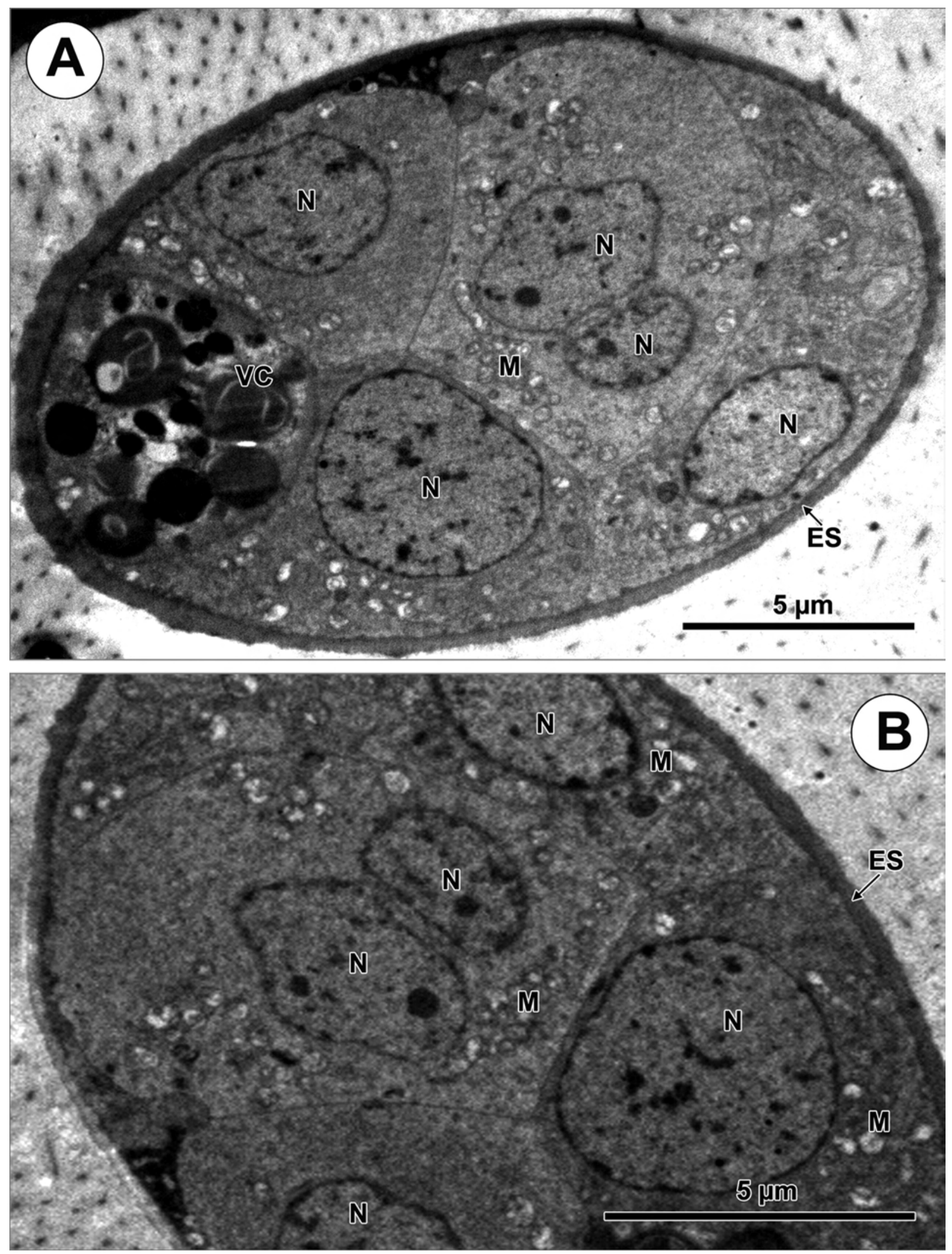

Fig. 5 A and B. Ultrastructure of embryonated eggs of Didymobothrium rudolphii which are composed of several blastomeres. Note: (a) the presence of three blastomeres with a single nucleus and one bi-nucleate blastomere with its two nuclei separated by only a narrow cytoplasmic lamina or fragmoplast; (b) part of the vitellocyte cytoplasm containing an abnormal type of lipid-like droplets with, dispersed among them, dark, irregularly shaped bodies resembling the foci of cytoplasmic degradation; (c) the rough surface of the shell surrounded by numerous cross- or obliquely sectioned polar filaments 
few sections of sperm axonemes are visible in the cytoplasm of the ovum, as is the presence of a thin ovum plasma membrane situated directly under the shell. Comparison of differences in the ultrastructure of the nuclei of the ovum and vitellocytes highlight evident differences in their size, electron density and other ultrastructural details of both cell types (Figs 1; 3A). These differences are more apparent at higher magnification; Figure 3A shows part of the nucleus of the ovum on the left side and of the vitellocyte in the right lower corner. Note the presence of numerous large, highly electrondense islands of heterochromatin in the nucleoplasm of the latter and the very homogeneous electron-lucent nature of that of the former (Fig. 3A).

\section{Ultrastructure of the shell of fully formed eggs}

The oval eggs in the middle and distal regions of the uterus already have fully developed, tanned shells with a high electron density and a slightly rough shell. The shell has a different thickness and electron density in the proximal, middle, distal and extreme distal-most regions of the uterus. In the latter, the narrower, anopercular pole of the egg is surrounded by a tuft of very thin polar filaments (Fig. 4A, B), whereas the opercular pole remains rounded and rather smooth. The tufts of freely dispersed polar egg filaments, when observed in the uterine lumen (Fig. 4A, B) exhibit, in longitudinal, oblique and crosssections, two ultrastructural components of different electron densities: a very thin and highly electron-dense core surrounded by a moderately electron-dense cortex. These likely correspond to the different chemical nature of the two regions.

\section{Ultrastructure of degenerating 'black eggs'}

Irregularly shaped, shrunken eggs, which represent degenerating eggs - the so-called 'black eggs' (Figs 4C; 6), were frequently observed in ultrathin sections. Such eggs are apparently quite common in this cestode species. Both the nuclei and the cytoplasm of these eggs are very compact. Their de-

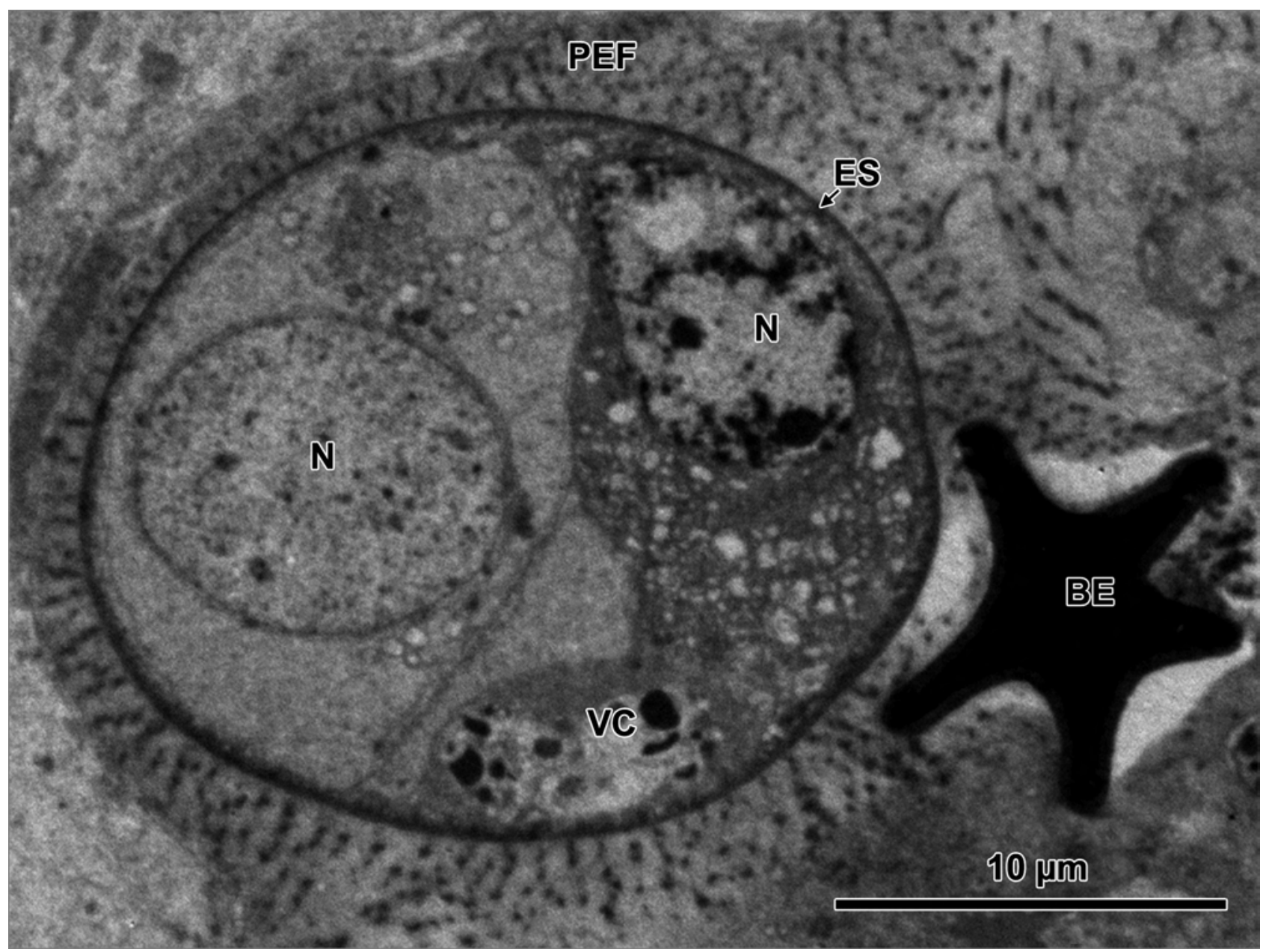

Fig. 6. A sagittal sections through one pole of an embryonated egg of Didymobothrium rudolphii containing two blastomeres of different size and ultrastructure and an adjacent star-shaped 'black egg', both surrounded by numerous polar filaments. Note: (a) two blastomeres of different types, showing variation in the size and ultrastructural characteristics of their nuclei and cytoplasm; (b) a small region of vitellocyte cytoplasm with dark, irregularly-shaped bodies resembling foci of cytoplasmic degradation 

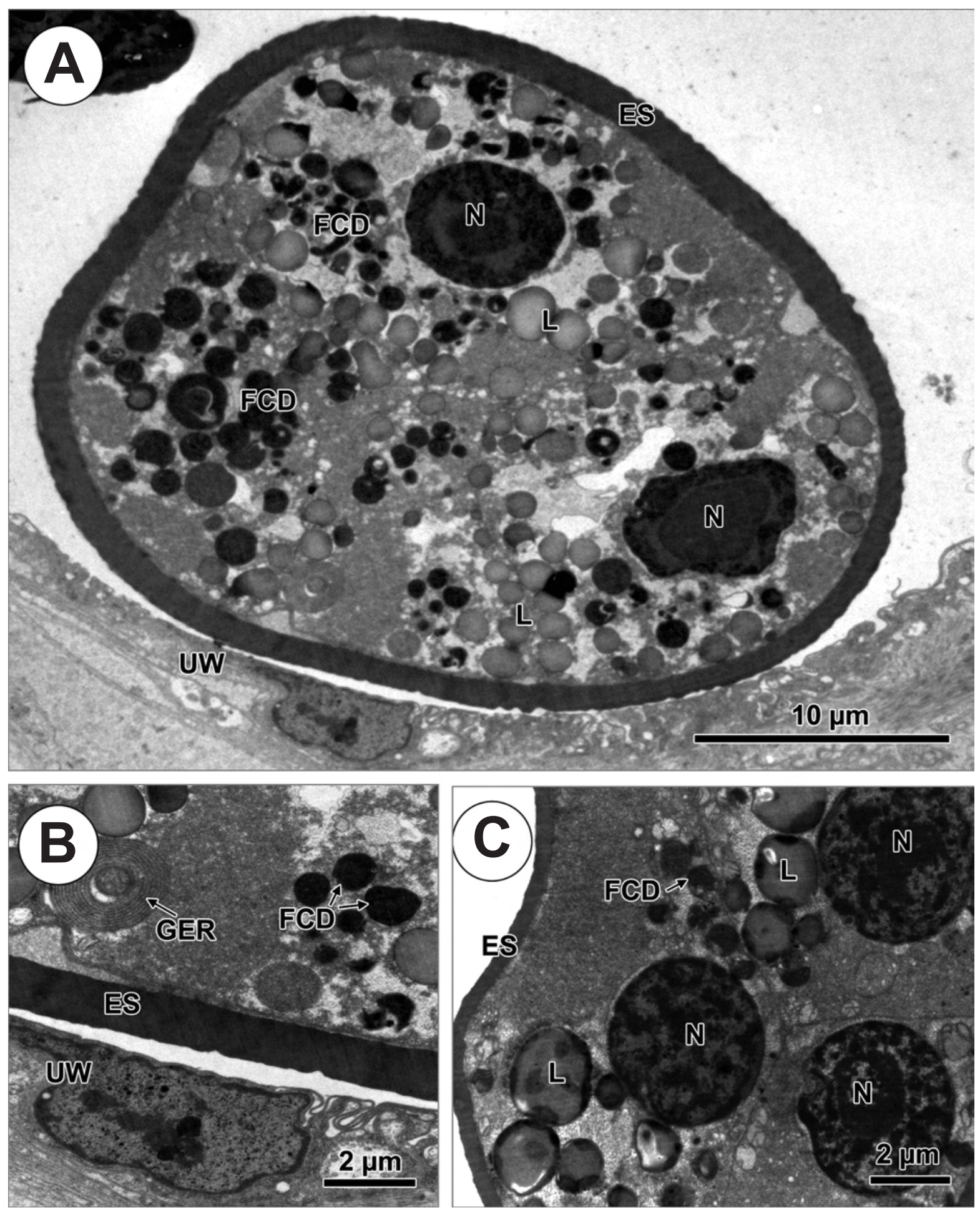

Fig. 7A-C. Cross-sections through the vitelline pole of an embryonated egg of Didymobothrium rudolphii showing different cellular components and inclusions of the vitelline syncytium (Fig. 7A). Note: (a) two electron-dense nuclei of vitellocytes with large nucleoli and numerous dense heterochromatin islands; (b) a great number of osmiophobic lipid droplets with a saturated chemical nature; (c) numerous dark, irregularly shaped bodies resembling foci of cytoplasmic degradation, which are more or less randomly dispersed among the lipid droplets (Fig. 7A). Inset: enlarged details showing glycogen accumulation in the cytoplasm of a vitellocyte. Fig. 7B and C represent enlarged details of the vitelline syncytium in the peripheral parts of the egg; in Fig. 7B, note several foci of cytoplasmic degradation and parallel concentric cisternae of GER in the left upper corner; in Fig. 7C, note: (a) three highly electron-dense nuclei of vitellocytes, with large nucleoli, numerous dense heterochromatin islands and foci of cytoplasmic degradation; (b) large lipid droplets of unequal electron density closely adjacent to the foci of cytoplasmic degradation, which may undergo autolysis 
generation usually starts at a very early, unembryonated stage, by which time a great majority of them are already surrounded by a thick, shrunken, electron-dense shell.

\section{Ultrastructural characteristics of early embryos composed of several blastomeres}

Some eggs in the middle and particularly in the distal parts of the uterus contain early embryos composed of four or five blastomeres visible in one ultrathin section (Figs 5; 6). For example, Figure 5A, B shows the presence of three blastomeres, each with a single nucleus and one bi-nucleate blastomere with its two nuclei separated by a very narrow cytoplasmic lamina resembling a fragmoplast. The adjacent vitellocyte cytoplasm contains numerous abnormal, lipid-like droplets, amongst which are dispersed dark, irregularly shaped bodies resembling foci of cytoplasmic degradation. At this stage, the rough surface of the shell is usually surrounded by numerous cross- or obliquely sectioned polar filaments.

Ultrastructural characteristics of the vitellocytes in fullyformed eggs

Ultrathin sections through the vitelline pole of an embryonated egg show different cellular components and inclusions in the vitelline syncytium (Fig. 7A). At this stage, two electron-dense nuclei of the vitellocytes still contain large nucleoli and numerous electron-dense islands of heterochromatin. The cytoplasm shows the presence of a great number of osmiophobic lipid droplets of a saturated chemical nature and numerous dark, irregularly-shaped bodies resembling foci of cytoplasmic degradation, which are more or less randomly dispersed among the lipid droplets (Figs 7A; 8). Enlarged details of the vitelline cytoplasm in the pe-

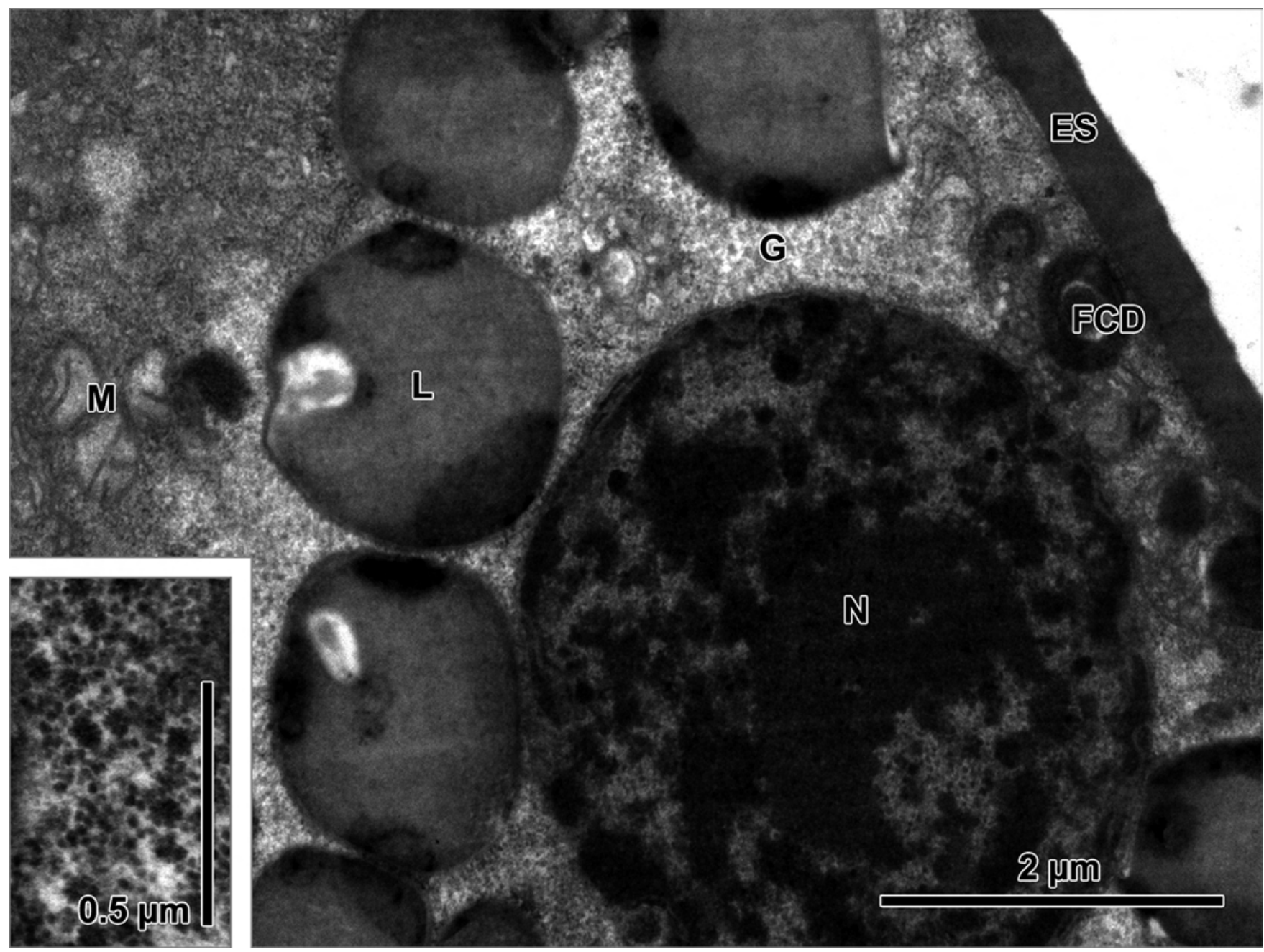

Fig. 8. High magnification TEM micrograph of Didymobothrium rudolphii showing details of the accumulation of nutritive material, in the form of large lipid droplets and glycogen, in the cytoplasm of the vitelline syncytium. Note: (a) the large nucleus of the vitellocyte with numerous dense islands of heterochromatin; (b) a few mitochondria; (c) several foci of cytoplasmic degradation; (d) a heavy accumulation of glycogen among the lipid droplets; (e) the atypical ultrastructure of the large lipid droplets which are probably undergoing autolysis. Inset: High power micrograph showing details of a heavy glycogen accumulation composed of $\alpha$-glycogen rosettes and single $\beta$-glycogen particles 
ripheral parts of the eggs (Fig. 7 B, C) show several foci of cytoplasmic degradation, and sometimes parallel, concentric cisternae of GER. Both Figures 7 and 8 illustrate ultrastructural details of several highly electron-dense nuclei of vitellocytes with large nucleoli and numerous dense islands of heterochromatin, foci of cytoplasmic degradation and large lipid droplets with an abnormal and unequal electron density. At this stage, such abnormal lipid droplets frequently remain in a close spatial relationship with the foci of cytoplasmic degradation. This may suggest that their initially homogeneous, highly osmiophobic content, a characteristic of chemically saturated lipids, undergoes some sort of autolytic process probably connected with a progressive resorption of these nutritive reserves by the developing embryos.

\section{Discussion}

Fertilisation, eggshell formation and early embryos of D. rudolphii: comparison with other cestodes

In D. rudolphii the ultrastructure of advanced stages of fertlisation generally resemble those described in Hymenolepis diminuta (see Świderski 1976) and four other cestodes belonging to different systematic groups (Świderski and Conn 1999, Świderski et al. 2004). Eggshell formation in D. rudolphii evidently differs from that reported in B. clavibothrium (see Świderski 1994a) and Schistosoma mansoni (see Świderski 1994b) because in the trematodes and lower cestodes it takes place in the ootype, whereas in D. rudolphii, as shown in present study, it occurs frequently in the proximal region of uterus. As indicated in our results, the intrauterine eggs of D. rudolphii are composed of several blastomeres of various sizes and ultrastructure, however, their cell divisions have never been observed. So far the evident cleavage divisions showing typical mitosis have been described only in light microscopical studies (for review see: Rybicka 1966) but never reported in TEM papers.

\section{Life cycle and embryonic development of spathebothriideans}

The dixenous life cycle of the Spathebothriidea is characterised by: (1) the absence of a coracidium; (2) the entry into water of the egg, where the embryos complete their development; and (3) the tendency for a monoxenous life cycle in the amphipod intermediate host (Wiśniewski 1932, Sandeman and Burt 1972, Gibson and Valtonen 1984, Protasova and Roytman 1995, Okaka 2000). Spathebothriidean eggs have a thick shell and are operculate. In some spathebothriidean genera (Diplocotyle, Didymobothrium) one pole of the egg gives rise to a bunch of filaments. The period that the eggs spend in water is said to be important for egg development and the formation of the oncosphere (Protasova and Roytman 1995).
According to Wiśniewski (1932), the embryo of the spathebothriidean Cyathocephalus truncatus (Pallas, 1781) develops ex utero from an unembyonated egg some days after release from the host into water. Such an operculate, intrauterine and unembryonated egg is illustrated in his paper. Apparently, the operculate eggs do not fully embryonate in utero. This author found that the embryo developed to some degree in eggs ex utero but not further than what would today be considered as early embryogeny. In fact, Wiśniewski found that, some days after the release of such eggs from the uterus into water, the developing larva within the egg would degenerate. Protasova and Roytman (1995), in their experimental work with $C$. truncatus eggs, also noted that the eggs can remain in water for a long time (up to 1.5 months) without any further development, but that this does occur in the presence of host faeces when the eggs leave the host's intestine naturally.

It their integrated account on the ecology and life cycle of Diplocotyle (as Bothrimonus), Sandeman and Burt (1972) reported that the adult tapeworms have a short life span in the fish host and occur seasonally. The single intermediate host is a common brackish-water gammarid. The operculate eggs, which contain an unciliated larva, possess characteristic polar filaments with an adhesive function. According to these authors, acquisition by the gammarid host is almost certainly by the ingestion of eggs. The larval form often attains sexual maturity within the gammarid host (see also Gibson and Valtonen 1984), with the accompanying production of apparently normal eggs. Sandeman and Burt (1972) concluded with the following statement: "Although it has been possible to infect fish host experimentally with larval stages, it has not yet been possible to infect gammarids with eggs obtained either from neotenic individuals in gammarids or from adults in the fish host".

The description on the life cycle presented in the paper of Sandeman and Burt (1972) represents a useful source of information for this discussion. As mentioned in the introduction, Burt and Sandeman (1969) considered both Didymobothrium and Diplocotyle as synonyms of Bothrimonus; decisions rejected by Gibson (1994) and apparently not supported by molecular studies (e.g. Marques et al. 2007, Olson et al. 2008). According to Sandeman and Burt (1972), the suggested life cycle of this parasite is summarised as follows: "Eggs released from gravid worms in the summer adhere to natural objects in water by means of their polar filaments. The embryos complete their development. On ingestion by a gammarid host an unciliated hexacanth larva emerges from the egg via the opercular opening and enters the hemocoel of the host. Overwintering takes place either within the egg or within a member of the overwintering population of gammarids. In the spring, growth and maturation of the parasite is rapid. Entry to the fish host is by ingestion of the gammarid. Further growth and maturation may take place in the fish host, in which dispersal is effected." As emphasised by these authors, "the evolution of the species has two impor- 
tant features: flexibility in the utilization of both its vertebrate and invertebrate hosts, and tendency towards a reduction in dependency on the fish host". Thus, according to Burt and Sandeman (1969), the structure of the eggs, the unciliated oncosphere and the nature of the life cycle of spathebothriidean tapeworms suggested "closer affinities to caryophyllaeid rather that to the other pseudophyllidean cestodes". Although molecular data, Olson and Tkach (2005), Olson et al. (2008), give no clear indication on this point, recent results on the ultrastructure of the eggs of the caryophyllidean cestode Wenyonia virilis Woodland, 1923 (Świderski et al., unpublished) support this hypothesis.

\section{Comparative ultrastructure of eggs of lower and higher ces- todes}

The ultrastructure of the eggs of $D$. rudolphii resembles to a great extent other intrauterine eggs described previously for the 'pseudophyllidean' Eubothrium salvelini (Schrank, 1790) (Świderski et al. 2005) and even the digenean Fasciola gigantica Cobbold, 1855 (Świderski et al. 2004). It is a fact that interesting homologies and analogies do exist in the fine structure of the eggs of lower cestodes and trematodes (Świderski $1994 a, b, c)$. There are, however, many reports of the presence of unembryonated, intrauterine eggs containing only fertilised oocytes in several orders of lower cestodes, such as that described in the 'pseudophyllidean' Bothriocephalus clavibothrium Ariola, 1899 (Świderski 1994a, Świderski and Mackiewicz 2004) and in some species of the Caryophyllidea (see Mackiewicz 1972, 1981).

It is interesting to note that all proteocephalideans (Świderski and Subilia 1978, Bruňanská 1999, Conn et al. 2009, Młocicki et al., in press) and all tetraphyllideans (Euzet and Mokhtar-Maamouri 1975, 1976; Mokhtar-Mamouri 1976) studied to date, despite their entirely aquatic life cycles, have, in terms of egg development, many more features in common with cyclophyllideans (Świderski 1968a, b; 1972, 1981, 2008; Świderski and Tkach 1997a, b; Świderski et al. 2001a, b; Młocicki et al. 2006; Jabbar et al. 2010) than with 'pseudophyllideans' (Kuperman 1988, Świderski 1994a, Świderski and Mackiewicz 2004, Świderski et al. 2005). In the trypanorhynch Grillotia erinaceus (Beneden, 1858), as described by McKerr (1985), only the first cleavage division of the zygote takes place in the uterus, and at this stage the egg is released into the external aquatic environment where the remainder of its embryonic development is completed. However, as commented by Campbell and Beveridge (1994, p. 70), in many other trypanorhynchs the intrauterine eggs may contain mature oncospheres.

Comparison of poly- and oligolecithality of the eggs of cestode parasites of fishes

In cestode parasites of fishes, there are two types of ectolecithal eggs which can be categorised as either oligolecithal or polylecithal, according to the number of vitellocytes per oocyte and the amount of vitelline material accumulated in each vitellocyte (Świderski and Mackiewicz 2007b). In all monozoic cestodes (Caryophyllidea, Gyrocotylidea, Amphilinidea) and some lower polyzoic eucestodes ('Pseudophyllidea', Spathebothriidea, Trypanorhyncha) polylecithal eggs are formed (for reviews see Świderski and Xylander 2000, Conn and Świderski 2008). In eggs of Didymobothrium rudolphii, the average number of vitellocytes per egg is 7-10, established by comparison of their numbers observed on different ultrathin sections, and corresponds with that observed in the Caryophyllidea (see Mackiewicz 1972), but differs greatly from the much higher number, of about 20-30, reported in 'pseudophyllideans' (Świderski 1994a). In contrast, in two other polyzoic orders, the Proteocephalidea (Świderski and Subilia 1978, Bruňanská 1999) and Tetraphyllidea (Euzet and Mokhtar-Maamouri 1975, 1976), oligolecithal eggs are formed. In the latter, the number of vitelline cells per fertilised oocyte as well as the number of eggshell globules and the amount of nutritive reserves ( $\alpha$ - and $\beta$-glycogen, lipid droplets) are greatly reduced. In the Proteocephalidea, which have predominantly aquatic life cycles, as well as the Cyclophyllidea, which have predominantly terrestrial life cycles, there are generally only one or, rarely, two vitellocytes per oocyte. TEM results for proteocephalideans (Conn et al. 2009) indicate the presence of only one vitellocyte per oocyte in the case of Proteocephalus longicollis (Zeder, 1800) and two vitellocytes per oocyte for Corallobothrium fimbriatum Essex, 1927. Two or three vitellocytes per oocyte have also been reported in two tetraphyllidean families; for example, only two vitellocytes were present in newly formed eggs of Acanthobothrium filicolle (Zschokke, 1887) (Euzet and MokhtarMaamouri 1975, Mokhtar-Maamouri 1976), whereas three vitellocytes are involved in the egg formation of Phyllobothrium gracile Wedl, 1855 (Mokhtar-Maamouri 1976, Euzet and Mokhtar-Maamouri 1976, for review see Świderski and Xylander 2000). Among the Cyclophyllidea, the enigmatic Mesocestoides lineatus (Goeze, 1792) incorporates two vitellocytes into its eggs (Conn 1988); this species uses terrestrial amniotes as definitive hosts, but the metacestode lives in both amniotes and amphibians, and the first intermediate host is as yet unknown.

In conclusion, with regard to the question of the polylecithality of $D$. rudolphii eggs, the average number of vitellocytes per egg is 7-10 and corresponds with that reported for caryophyllideans, whereas the number in 'pseudophyllideans' is generally much higher. However, the chemical nature of the nutritive reserves accumulated in the vitellocytes of these two cestode orders is very different. In the caryophyllideans they are composed exclusively of cytoplasmic and nuclear glycogen present in two forms, $\alpha$-glycogen rosettes and individual $\beta$-glycogen particles; whereas in the eggs of 'pseudophyllideans' and D. rudolphii these nutritive reserves for the developing embryos are accumulated in the form of numerous lipid droplets and a rather moderate amount of glycogen. 
Oviparity and different degrees of ovoviparity in cestode parasites of fishes

The life cycle of the 'pseudophyllidean' Bothriocephalus clavibothrium (see Świderski 1994b) exhibits a good example of oviparity, as the eggs are voided from the uterus in an unembryonated stage, even before the first cleavage division of the fertilised ovum, and all embryonic development up to the hatching of the ciliated larva takes place in the aquatic environment. Such oviparous eggs usually require thick, hard shells for the protection of the embryo and a large amount of food reserves for its development. In the spathebothriidean D. rudolphii (present study) and the caryophyllidean Wenyonia virilis (Świderski et al. 2009, Świderski et al., unpublished) the eggs are voided from the uterus only after several cleavage divisions in utero and are already at an early embryonic stage composed of several not fully-differentiated blastomeres of different sizes and ultrastructure. Nevertheless, in both species, we can refer to the development as an early stage of ovoviviparity.

Developing the ideas of Janicki (1918), who subdivided all cestodes into the paraphyletic groups 'Polyvitellaria' and 'Monovitellaria', Jarecka (1975) proposed referring to the Polyvitellaria as oviparous, as they produced unembryonated eggs and started their development in water, and the Monovitellaria as viviparous, as they produced embryonated eggs with fully or partly differentiated oncospheres. Because cestode oncospheres are always surrounded by oncospheral envelopes (i.e. the final derivatives of the embryonic envelopes plus vitelline and uterine secretions) when released from the parent, there is no true viviparity. Therefore, rather than being viviparous, many cestodes may exhibit different degrees of ovoviviparity, as originally suggested by Tinsley (1983). Furthermore, there is a great variation in the stage of embryonation at which the eggs of different cestodes of fishes are released from the parent. In a great majority of the 'pseudophyllideans', unembryonated eggs are released before the first cleavage division and contain only a fertilised oocyte with $20-30$ vitellocytes enclosed within a thick, operculate or anoperculate shell (Świderski 1994b, c; Świderski et al. 2005). In the trypanorhynch Grillotia erinaceus (Beneden, 1858), the life cycle of which was described by Ruszkowski (1932), the eggs are released immediately after the first equal cleavage division and contain only two macromeres of equal size (McKerr 1985). Interesting variations are observed in the Caryophyllidea, where, with the exception of Archigetes, in which embryonation is usually completed in utero, and four other genera, Wenyonia, Hunterella, Djombangia and Biacetabulum, where it begins in utero but is completed in water, the eggs of most other studied members of this order have been found to be unembryonated when shed (Mackiewicz 1972). For these reasons, in this group too, it may be more accurate to refer to different degrees of ovoviviparity, as initially suggested by Świderski and Mackiewicz (2007a), rather than using the two extreme cases of oviparity and viviparity, as originally proposed by Jarecka (1975).

\section{Apoptosis during the embryonic development of cestodes}

As described above, the irregularly shaped, shrunken eggs of D. rudolphii, which represent degenerating eggs, or so-called 'black eggs', are quite common in this species. They are even more common in the 'pseudophyllidean' Eubothrium salvelini (Schrank, 1790), where their ultrastructure was described by Świderski et al. (2005). In both the latter species and in D. rudolphii, egg maturation is not simultaneous, since, together with mature eggs containing fully differentiated oncospheres, numerous small, immature, unfertilised, nonviable eggs can be found; these represent a very high percentage of all eggs produced in the case of E. salvelini. Another good example of apoptosis, or programmed cell death, in cestodes is the production and destiny of vitellocytes. Once their two important functions, eggshell formation and the storage of nutritive reserves for the developing embryo, are accomplished, they undergo a progressive degeneration and autolysis, during which their cell organelles and inclusions become reabsorbed by the differentiating larva. Apoptosis of both vitellocytes and some part of the smallest blastomeres or micromeres also takes place during both early and more advanced stages of the embryonic development and blastomere differentiation. As reported by Rybicka (1966) and Świderski (1968b), the degeneration of numerous micromeres results in a great reduction in the numbers of oncospheral cells, a common feature for both lower (Świderski 1994a) and higher cestodes (Świderski 1968a, b; 1981).

\section{Concluding remarks}

When compared with similar eggs of some caryophyllideans (Mackiewicz 1972, Świderski et al., unpublished), the present data on the ultrastructure of the intrauterine eggs of Didymobothrium rudolphii, which contain a restricted number of vitellocytes per ovum, a limited polylecithality and early embryos composed of several blastomeres, could be used to support a relationship between the Spathebothriidea and the former order. However, caryophyllidean vitellocytes have a completely different ultrastructure, exhibiting a heavy accumulation of both cytoplasmic and nuclear glycogen and a complete lack of lipid droplets, which tend to negate such a relationship. It seems that such limited polylecithality in both of the above-mentioned orders may be more associated with some similarity in their life cycles, such as the waiting period for egg ingestion by the intermediate host, than with any close phylogenetic interconnections. Progenesis in spathebothriideans might suggest a closer link with the Caryophyllidea, as this also occurs in Archigetes; however, this is strictly a developmental character, which may be a secondarily derived characteristic without much phylogenetic significance. On other hand, features, such as the polypleuroid body form, with an alternating dorsal-ventral gonopore position in some species, the life-cycle with an arthropod as the first host, and the utilisation of marine and freshwater teleosts and chon- 
drosteans as definitive hosts, would seem to indicate that spathebothriideans are more closely related to the 'Pseudophyllidea'. As indicated above, molecular data (Olson and Tkach 2005, Olson et al. 2008) to date give no clear insights into these relationships.

It seems, however, that further investigations into the ultrastructure of the eggs of other spathebothriideans, such as Cyathocephalus truncatus and the potentially monoxenous, progenetic Diplocotyle olrikii, and eggs of other closely related lower cestodes may prove useful for providing additional data for the analysis of interrelationships among the lower tapeworms.

Acknowledgements. The authors extend their appreciation to Drs Peter Olson (Natural History Museum, London) and Joana Marques (Univerasidade de Lisboa) for help with the collection of the tapeworms, which was financed by CIIMAR and the Treaty of Windsor Programme, nos B-13/05-2005/2006 and B-58/07-2007/2008, between the NHM, UK and FCUP, Portugal. They are also very grateful to Professor John S. Mackiewicz (State University of New York at Albany) for discussion on the evolutionary relationships of the Caryophyllidea in relation to other cestode groups. The valuable, constructive comments of three anonymous referees are also gratefully acknowledged. The present study was also supported by the Russian Foundation for Fundamental Research project No. 09-04-00342a to LGP. The authors would like to thank the staff of the Centre of Electron Microscopy, Institute of Biology of Inland Waters, Borok, Russia for the technical assistance.

\section{References}

Bruňanská M. 1999. Ultrastructure of primary embryonic envelopes of Proteocephalus longicollis. Helminthologia, 34, 9-13.

Burt M.D.B., Sandeman I.M. 1969. Biology of Bothrimonus (= Diplocotyle) (Pseudophyllidea: Cestoda). Part I. History, description, synonymy, and systematics. Journal of the Fisheries Research Board of Canada, 26, 975-996.

Campbell R.A., Beveridge I. 1994. Order Trypanorhyncha Diesing, 1863. In: (Eds. L.F. Khalil, A. Jones and R.A. Bray) Keys to the Cestode Parasites of Vertebrates. CAB International, Wallingford, 51-148.

Conn D.B. 1988. Development of the embryonic envelopes of Mesocestoides lineatus (Cestoda: Cyclophyllidea). International Journal of Invertebrate Reproduction and Development, 14, 119-130.

Conn D.B., Młocicki D., Świderski Z. 2009. Ultrastructure of the early gravid uterus of Corallobothrium fimbriatum (Cestoda: Proteocephalidea). Parasitology Research, 105, 986-996. DOI: 10.1007/S00436-009-1487-9.

Conn D.B., Świderski Z. 2008. A standardised terminology of the embryonic envelopes and associated developmental stages of tapeworms (Platyhelminthes: Cestoda). Folia Parasitologica, $55,42-52$

Euzet L., Mokhtar-Maamouri F. 1975. Développement embryonnaire de trois Cestodes du genre Acanthobothrium (Tetraphyllidea, Onchobothriidae). Annales de Parasitologie Humaine et Comparée, 50, 675-690.

Euzet L., Mokhtar-Maamouri F. 1976. Développement embryonnaire de deux Phyllobothriidae (Cestoda, Tetraphyllidea). Annales de Parasitologie Humaine et Comparée, 51, 309-327.

Gibson D.I. 1994. Order Spathebothriidea Wardle and McLeod, 1952. In: (Eds. L.F. Khalil, A. Jones and R.A. Bray) Keys to the Cestode Parasites of Vertebrates. CAB International, Wallingford, 15-19.

Gibson, D.I., Valtonen E.T. 1984. Two interesting records of tapeworms from Finnish waters. Aquilo (Ser. Zoologica), 22, 4549.

Hoberg E.P., Mariaux J., Brooks D.R. 2001. Phylogeny among orders of the Eucestoda (Cercomeromorphae): integrating morphology, molecules and total evidence. In: (Eds. D.T.J. Littlewood and R.A. Bray) Interrelationships of the Platyhelminthes. Taylor \& Francis, London, 112-126.

Jabbar A., Swiderski Z., Mlocicki D., Beveridge I., Lightowlers M.W. 2010. The ultrastructure of taeniid cestode oncospheres and localization of host-protective antigens. Parasitology, 137, 521-535. DOI: 10.1017/S0031182009991260.

Janicki C. 1918. Neue Studien über post-embryonale Entwicklung und Wirstwechsel bei Bothriocephalen. I. Triaenophorus nodulosus (Pall.). Correspondenz-Blatt für Schweizer Ärzte, 48 (40), 1343-1349.

Jarecka L. 1975. Ontogeny and evolution of cestodes. Acta Parasitologica Polonica, 23, 93-114.

Kuchta R., Scholz T., Brabec J., Bray R.A. 2008. Suppression of the tapeworm order Pseudophyllidea (Platyhelminthes: Eucestoda) and the proposal of two new orders, Bothriocephalidea and Diphyllobothriidea. International Journal for Parasitology, 38, 49-55. DOI: 10.1016/j.ijpara.2007.08.005.

Kuperman B.I. 1988. Functional morphology of lower cestodes: ontogenetic and evolutionary aspects. Nauka, Leningrad, 167 pp. (In Russian).

Mackiewicz J.S. 1972. Caryophyllidea (Cestoidea): a review. Experimental Parasitology, 31, 417-512. DOI: 10.1016/00144894(72)90103-8.

Mackiewicz J.S. 1981. Caryophyllidea (Cestoidea): evolution and classification. Advances in Parasitology, 19, 139-206. DOI: 10.1016/S0065-308X.

Mariaux J., Olson P.D. 2001. Cestode systematics in a molecular era. In: (Eds. D.T.J. Littlewood and R.A. Bray) Interrelationships of the Platyhelminthes. Taylor \& Francis, London, 127-134.

Marques J.F., Santos F.J., Gibson D.I., Cabral H.N., Olson P.D. 2007. Cryptic species of Didymobothrium rudolphii (Cestoda: Spathebothriidea) from the sand sole Solea lascaris, off the Portuguese coast with analysis of their molecules, morphology, ultrastructure and phylogeny. Parasitology, 134, 1057-1072. DOI: $10.1017 / \mathrm{S} 0031182007002491$.

McKerr G. 1985. The fine structure and physiology of a trypanorhynch tapeworm Grillotia erinaceus. PhD Thesis, The Queen's University of Belfast, Northern Ireland, UK, 205 pp.

Młocicki D., Świderski Z., Miquel J., Eira C., Conn D.B. 2006. Cellular organization of the oncosphere of Mosgovoyia ctenoides (Cestoda: Anoplocephalidae). Journal of Parasitology, 92, 953-961. DOI: 10.1645/GE-790R1.1.

Młocicki D., Świderski Z., Conn D.B. 2010. Ultrastructure of the early embryonic development of Corallobothrium fimbriatum (Cestoda: Proteocephalidea). Journal of Parasitology (in press).

Mokhtar-Maamouri F. 1976. Etude ultrastructurale de la gamétogénèse et des premiers stades du développement embryonaire de deux cestodes Tetraphyllidea. Thèse du doctorat d'Etat, U.S.T.L, Montpellier, 224 pp.

Okaka C.E. 2000. Maturity of the procercoid of Cyathocephalus truncatus (Eucestoda: Spathebothriidea) in Gammarus pulex (Crustacea: Amphipoda) and the tapeworms life cycle using the amphipod as the sole host. Helminthologia, 37, 153-157.

Olson P.D., Littlewood D.T.J., Bray R.A., Mariaux J. 2001. Interrelationships and evolution of the tapeworms (Platyhelminthes: Cestoda). Molecular Phylogeny and Evolution, 19, 443-467. DOI: 10.1006/mpev.2001.0930. 
Olson P.D., Tkach V.V. 2005. Advances and trends in the molecular systematics of the parasitic Platyhelminthes. Advances in Parasitology, 60, 165-243. DOI: 10.1016/S0065-308X.

Olson P.D., Poddubnaya L.G., Littlewood D.T.J., Scholz T. 2008. On the position of Archigetes and its bearing on the early evolution of the tapeworms. Journal of Parasitology, 94, 898-904. DOI: $10.1645 / \mathrm{GE}-1456.1$.

Poddubnaya L.G., Gibson D.I., Olson P.D. 2007. Ultrastructure of the ovary, ovicapt and oviduct of the spathebothriidean tapeworm Didymobothrium rudolphii (Monticelli, 1890). Acta Parasitologica, 52, 127-134. DOI: 10.2478/s11686-0070014-3.

Poddubnaya L.G., Gibson D.I., Świderski Z., Olson P.D. 2006. Vitellocyte ultrastructure in the cestode Didymobothrium rudolphii (Monticelli, 1890): possible evidence for the recognition of divergent taxa within the Spathebothriidea. Acta Parasitologica, 51, 255-263. DOI: 10.2478/s11686006-0039-z.

Protasova E.N., Roytman V.A. 1995. Cyathocephalates, tapeworm helminths of marine and freshwater fish (Cestoda: Pseudophyllidea: Cyathocephalata). Essentials of Cestodology. Vol. 12. Institute of Parasitology, Russian Academy of Sciences, Moscow, 134 pp. (In Russian).

Renaud F., Gabrion C. 1988. Speciation in Cestoda: evidence for two sibling species in the complex Bothrimonus nylandicus (Schneider, 1902) (Cestoda: Cyathocephalidae). Parasitology, 97, 139-147. DOI: 10.1017/S0031182000066816.

Ruszkowski J.S. 1932. Etudes sur le cycle évolutif et la structure des cestodes de mer. III. Le cycle évolutif de tétrarhynque Grillotia erinaceus (van Beneden, 1858). Comptes Rendus Mensuels des Séances de la Classes des Sciences Mathématiques et Naturelles. Académie Polonaise des Sciences et des Lettres, 9,6 .

Rybicka K. 1966. Embryogenesis in cestodes. Advances in Parasitology, 4, 107-186. DOI: 10.1016/S0065-308X.

Sandeman I.M., Burt M.D.B. 1972. Biology of Bothrimonus (= Diplocotyle) (Pseudophyllidea: Cestoda). Part II. Ecology, life cycle and evolution; a review and synthesis. Journal of the Fisheries Research Board of Canada, 29, 1381-1395.

Świderski Z. 1968a. Electron microscopy of embryonic envelope formation by the cestode Catenotaenia pusilla. Experimental Parasitology, 23, 104-113. DOI: 10.1016/0014-4894.

Świderski Z. 1968b. An electron microscopic evidence of the degeneration of some micromeres during the embryonic development of the cestode Catenotaenia pusilla (Goeze, 1782) (Cyclophyllidea, Catenotaeniidae). Zoologica Poloniae, 18, 469-474.

Świderski Z. 1972. La structure fine de l'oncosphere du cestode Catenotaenia pusilla (Goeze, 1782) (Cyclophyllidea, Catenotaeniidae). La Cellule, 69, 207-237.

Świderski Z. 1976. Fertilization in the cestode Hymenolepis diminuta (Cyclophyllidea, Hymenolepididae). In: (Ed. B. Feldman-Mushan) Proceedings of the 6th European Congress on Electron Microscopy, 14-20 September 1976, Jerusalem, Israel, 311-312.

Świderski Z. 1981. Reproductive and developmental biology of the cestodes. In: (Eds. W.A. Clark and T.S. Adams) Advances in invertebrate reproduction. Elsevier/North Holland Biomedical Press, New York, Amsterdam, Oxford, 365-366.

Świderski Z. 1994a. Origin, differentiation and ultrastructure of egg envelopes surrounding the miracidia of Schistosoma mansoni. Acta Parasitologica, 39, 64-72.

Świderski Z. 1994b. Origin, differentiation and ultrastructure of egg envelopes surrounding the coracidia of Bothriocephalus clavibothrium. Acta Parasitologica, 39, 73-81.
Świderski Z. 1994c. Homology and analogy in of egg envelopes surrounding the coracidia of Bothriocephalus clavibothrium and miracidia of Schistosoma mansoni. Acta Parasitologica, 39, $123-130$.

Świderski Z. 2008. Biodiversity of parasite eggs: their importance for disease dissemination and diagnostics. In: Commemorative Volume of Proceedings Published on the Occasion of the International Conference Dedicated to the 130th Anniversary of the Birthday of Academician K.I. Skrjabin, 453-459.

Świderski Z., Bruňanská M., Młocicki D., Conn D.B. 2005. Ultrastructure of the oncospheral envelopes in the pseudophyllidean Eubothrium salvelini (Schrank, 1790). Acta Parasitologica, 50, 312-318.

Świderski Z., Conn D.B. 1999. Ultrastructural aspects of fertilization in Proteocephalus longicollis, Inermicapsifer madagascariensis, and Mesocestoides lineatus (Platyhelminthes, Cestoda). Acta Parasitologica, 44, 19-30.

Świderski Z., Conn D.B., Miquel J., Młocicki D. 2004. Fertlization in the cestode Gallegoides arfaai (Mobedi et Ghadirian, 1977) Tenora et Mas-Coma, 1978 (Cyclophyllidea, Anoplocephalidae). Acta Parasitologica, 49, 108-115.

Świderski Z., Mackiewicz J.S. 2004. Ultrastructural studies on the cellular organisation of the coracidia of the cestode Bothriocephalus clavibothrium Ariola, 1899 (Pseudophyllidea, Bothriocephalidae). Acta Parasitologica, 49, 116-139.

Świderski Z., Mackiewicz J.S. 2007a. Ovoviviparity in cestode parasites of fishes. In: Proceedings of the 7th International Symposium on Fish Parasites, Viterbo, Italy. Parassitologia, 49, Suppl. 2, 393.

Świderski Z., Mackiewicz J.S. 2007b. Ultrastructure of polylecithal and oligolecithal eggs of cestode parasites of fishes: comparative TEM study. In: Proceedings of the 7th International Symposium on Fish Parasites, Viterbo, Italy. Parassitologia, 49, Suppl. 2, 394.

Świderski Z., Młocicki D., Mackiewicz J.S., Miquel J., Ibraheem M.H., Bruňanská M. 2009. Ultrastructure and cytochemistry of vitellogenesis in Wenyonia virilis Woodland, 1923 (Cestoda, Caryophyllidea). Acta Parasitologica, 54, 131-142. DOI: 10.2478/s11686-009-0028-0.

Świderski Z., Ndiaye P.I., Tkach V., Miquel J., Marchand B., Chomicz L., Sereda M.J. 2001a. Ultrastructural study of the embryonic development of the anoplocephalid cestode Anoplocephaloides dentata, intestinal parasite of Arvicolidae rodents. I. Egg envelope formation. Acta Parasitologica, 46, 171-185.

Świderski Z., Ndiaye P.I., Miquel J., Tkach V., Marchand B., Chomicz L., Grytner-Zięcina B., Sereda M.J. 2001b. Ultrastructural study of the embryonic development of the anoplocephalid cestode Anoplocephaloides dentata, intestinal parasite of Arvicolidae rodents. II. Differentiation and cellular organisation of the oncosphere. Acta Parasitologica, 46, 280-292.

Świderski Z., Ndiaye P.I., Miquel J. 2004. Electron microscope studies on egg formation and ultrastructure of the unembryonated, intrauterine eggs of Fasciola gigantica Cobbold, 1856 (Trematoda, Digenea). (Eds. S. Mas-Coma, M.D. Bargues, J.G. Esteban and M.A. Valero) Proceedings of the 9th European Multicolloquium of Parasitology, July 18-23, 2004, Valencia, Spain, Abstract: 1252(I0), 604.

Świderski Z., Subilia L. 1978. Electron microscopy of embryonic envelope formation by the cestode Proteocephalus longicollis (Zeder, 1800) (Proteocephalidea). In: (Eds. P. Broderoo and W. Priester) Proceedings of the 9th International Congress on Electron Microscopy, 1-9 August, 1978, Toronto, Canada, 2, 444-445. 
Świderski Z., Tkach V.V. 1997a. Ultrastructure of the infective eggs of the hymenolepidid cestode Ditestolepis tripartita (Zarnowski, 1955), a parasite of shrews. Acta Parasitologica, 42, $46-54$.

Świderski Z., Tkach V.V. 1997b. Ultrastructural studies on the cellular organisation of the oncosphere of the nematotaeniid cestode Nematotaenia dispar (Goeze, 1782). Acta Parasitologica, 42, 158-167.

Świderski Z., Xylander W.E.R. 2000. Vitellocytes and vitellogenesis in cestodes in relation to development, egg production and life cycle. International Journal for Parasitology, 30, 805817. DOI: 10.1016/S0020-7519(00)00066-7.

Tinsley R.C. 1983. Ovoviviparity in platyhelminth life cycles. Parasitology, 86, 161-196. DOI: 10.1017/S0031182000050885.
Waeschenbach A., Webster B.L., Bray R.A., Littlewood D.T.J. 2007. Added resolution among ordinal level relationships of tapeworms (Platyhelminthes: Cestoda) with complete small and large subunit nuclear ribosomal RNA genes. Molecular Phylogeny and Evolution, 45, 311-325. DOI: 10.1016/j.ympev. 2007.03.019.

Wiśniewski L.W. 1932. Cyathocephalus truncatus Pallas. II. Allgemeine Morphologie. Bulletin International de l'Académie Polonaise des Sciences et des Lettres. Class des Sciences Mathématiques et Naturelles, Série B: Sciences Nat. (II), (1932), 311-327.

(Accepted April 21, 2010) 